Goldschmidt 2021 Abstract

https://doi.org/10.7185/gold2021.8036

\section{New assemblages of Paleoproterozoic organic-walled microfossils and implications for eukaryogenesis and the early evolution of eukaryotes}

\author{
EMMANUELLE J. JAVAUX ${ }^{1}$, SAM SPINKS ${ }^{2}$ AND \\ MARCUS KUNZMANN ${ }^{3}$ \\ ${ }^{2}$ CSIRO - Mineral Resources \\ Presenting Author: ej.javaux@uliege.be
}

${ }^{1}$ Université de Liège

${ }^{3}$ CSIRO

We report new assemblages of well-preserved organic-walled microfossils from the $>1.648 \mathrm{Ga}$ Mallapunyah Formation (McArthur Group) and the 1.78-1.73 Ga McDermott Formation (Tawallah Group), McArthur Basin, Australia. These assemblages include entangled filamentous sheaths, pseudobranching filaments and akinete-like vesicles of probable cyanobacterial origin; smooth-walled vesicles, with diverse shapes, wall textures and size (up to few hundred microns), excystment structures or budding; and vesicles ornamented with concentric striations (Valeria), equatorial flange (Simia), organic plates (Dictyosphaera), and processes and other expansions from the vesicle wall (Tappania). Known fossil bacterial walls and sheaths do not show such wall ornamentation. Although filamentous protrusions are known in one archaeon and in PVC Bacteria, showing that prokaryotes may show complex morphologies supported by their cytoskeleton, the microfossils size strongly differ by one or two orders of magnitude from them. In contrast, the morphological complexity of fossils reported here is only known in eukaryotes and implies cytological sophistication for the synthesis of organic plates, external equatorial outgrowth, internal concentric ridges, and diverse protrusions indirectly evidencing the presence of a cytoskeleton. Collectively, these assemblages reveal an ecosystem with cyanobacterial mat fragments, diverse prokaryotic or eukaryotic cells, various stages of life cycle, and ornamented protists, known in the late PaleoproterozoicMesoproterozoic. This record pushes back the minimum age of eukaryotic fossils, previously reported at $\sim 1.65 \mathrm{Ga}$ in China and Australia.

Asgard Archaeal genomes (closest relatives to eukaryotes) suggest that some cellular complexity, including the cytoskeleton, may have emerged before other eukaryotic cellular features characterizing LECA, such as the mitochondria, nucleus and endomembrane system, but the timing and relative order of evolution of these traits through eukaryogenesis is debated. The early protists reported here thrived in anoxic-suboxic sulfurlimited near-shore water, close to cyanobacterial mats. Their distinctive complex morphology suggests an earlier evolution of simpler stem eukaryotes (before LECA), in the older Paleoproterozoic or Archean record preserving large unornamented microfossils. Because of their long stratigraphic range, the fossils reported here could represent stem eukaryotes pursuing their evolution for some time after crown-group diversification, or alternatively, they provide a minimum age for LECA, consistent with several molecular clocks, perhaps with metabolically versatile mitochondria 